\title{
ОСАДКООБРАЗОВАНИЕ И ГЕОЛОГИЧЕСКОЕ РАЗВИТИЕ ОЗЕР ИЛЛУКАСКОГО КАМОВОГО ПОЛЯ
}

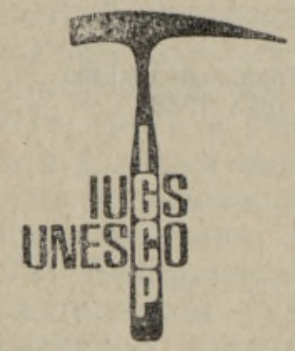

Проект « Палеогидрология»

Для установления особенностей осадкообразования и геологического развития озер камовых полей нами в качестве эталонного участка было выбрано Иллукаское камовое поле в северо-восточной части республики, где в пределах 30 км² $^{2}$ расположено 40 озер. Из них изучено 7 - Ряэкъярв, Коннъярв, Куртна, Ахнеярв, Валгеярв, Ряэтсма и Хаугъярв, - разместившиеся почти равномерно по всему камовому полю (рис. 1). Хотя биология озер, геологические и гидрогеологические условия местности были хорошо изучены (Mäemets, 1977; Tšeban, 1975), все же отсутствовали данные об условиях залегания, составе и биостратиграфии донных отложений озер. Поэтому в данной статье основное внимание уделено именно этим вопросам.

Изученные озера Иллукаского камового поля небольшие, площадью менее 10 га, за исключением Куртна и Ряэтсма, но сравнительно глубокие: Ряэтсма - 17 м, Ахнеярв и Валгеярв - 10 м. Уровень воды, поддерживавшийся на абсолютных высотах от 41,3 (Коннъярв) до 47,4 м (Куртна), был снижен на 2-3 м после того как построили водопровод Ахтме-Иллука. В плане озера овальные, продолговатые, грушеобразные или изометричные, конфигурацией повторяющие очертания окружающих озера камов. Склоны озерных котловин крутые, близкие к уклону естественного откоса песка. Берега песчанистые, на коротких участках заторфованные или трясинистые с узкой литоральной полосой. Питающиеся подземными, поверхностными и атмосферными осадками озера замкнутые или источные, со средней или низкой минерализацией озерной воды (Mäemets, 1977). Слабопроточными являются лишь озера Ряэтсма и Куртна.

Просадочные гляциокарстовые котловины озер расчленены песчаными буграми и в различной степени наполнены сапропелем. Типичные позднеледниковые алеврито-пелитовые отложения отсутствуют. Тонкие линзы последних найдены в профундале наиболее крупных озер (Ряэтсма, Куртна) (рис. 2). На водноледниковых и озерных песках залегает сравнительно однородный по всему разрезу и акватории тонкодетритовый сапропель, нижняя часть которого из-за высокого содержания железа быстро окисляется и темнеет. Максимальная мощность сапропеля колеблется в больших пределах: от 1,4 м в оз. Валгеярв до 8 м в оз. Ряэтсма, показывающих, что в озерах со сходным режимом питания интенсивность осадконакопления резко различается в зависимости от гидрохимизма, гидробиологических и морфометрических характеристик и проточности конкретного водоема. Например, в

Рис. 1. Расположение изученных озер в камовом поле Иллука. 1 - изученные озера, 2 - геологически неизученные. 


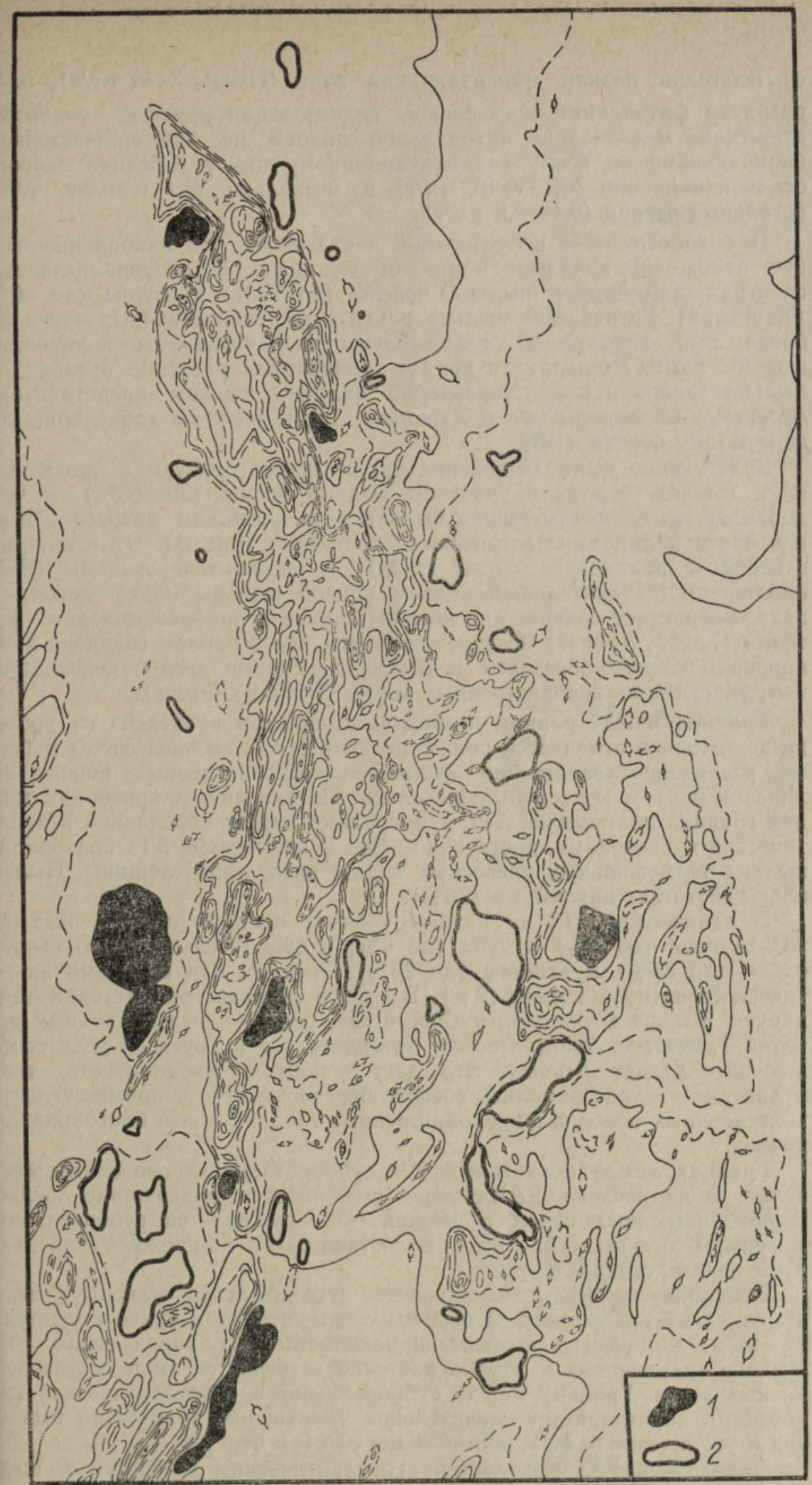


оз. Валгеярв низкая минерализация воды $\left(\mathrm{HCO}_{3}^{1} 3-6\right.$ мг/л), мало. развитая фитопланктонная флора, значительная крутизна склонов и отсутствие мелкооводной литоральной полосы не благоприятствовали биопродукции по всему седиментационному циклу. Средняя скорость осадконакопления $(0,1-0,15 \mathrm{mм} / \Gamma)$ в несколько раз меньше, чем в остальных озерах $(0,4-0,8 \mathrm{~mm} / г)$.

Палинологичелкие исследования показывают, что накопление озерных отложений началось в раннем голоцене. В спорово-пыльцевых спектрах доминирует пыльца березы (до 73\%) i сосны (до 30\%) (Хаугъярв). Встречается пыльца ольхи и широколиственных пород (не более $5 \%$ ). Кустарники представлены незначительным количеством пыльцы Salix, Hippophaё и др. Из травянистых растений преобладает пыльца злаков и осок. Характерно наличие пыльцы представителей семейства Chenopodiaceae и Artemisia. Такие спектры характерны для палинозоны березы (РВ).

Залегающие выше отложения также характеризуются преобладанием пыльцы березы с участием пыльцы сосны $(30-60 \%)$, к чему добавляются единичные зерна пыльцы вяза и лещины, которые в верхней части палинозоны встречаются постоянно (рис. 3). Этот интервал отнесен к палинозоне сосны (BO1). В палинозоне лещины (BO2) наблюдается значительный подъем кривой пыльцы ольхи, лещины и вяза. Возрастает содержание пыльцы злаков и прибрежно-водных растений (Typha, Nyphar). Следует отметить, что в раннем голоцене доминировали сосново-березовые и березово-сосновые леса с незначительным участием широколиственных пород (Ulmus, Corylus).

Граница между ранним и средним голоценом проведена на уровне, выше которого отмечается снижение количества пыльцы сосны и березы, увеличение содержания пыльцы широколиственных пород (вяз, липа) и подъем кривой пыльцы ольхи. По указанным критериям нижняя граница палинозоны AT1, т. е. граница между бореальной и атлантической хронозонами, достаточно ясна. В палинозоне АT1 преобладает пыльца термофильных древесных пород: вяза, липы, лещины. Пыльца ольхи достигает максимума $(36 \%)$.

В палинозоне АТ2 на разных уровнях обильна пыльца вяза (до $13 \%$ ), липы (до $8 \%$ ) и дуба (до 6\%) и сравнительно много пыльцы ольхи (до $32 \%$ ) и лещины (до $20 \%$ ). Пыльцы ели во время климатического оптимума мало $(2 \%)$. В группе травянистых растений доминируют пыльца Gramineae и Cyperaceae, pеже - пыльца водных растений Typhaceae, Sparganiaceae, Nymphaeaceae и другие. Среди споровых преобладает Bryales. Это дает основание предполагать, что в атлантике распространились сосново-березовые леса с примесью широколиственных пород и широколиственные леса на более благоприятных почвах.

Граница между атлантической и суббореальной хронозонами менее ясная. В палинозоне SB1 сильно уменьшается содержание пыльцы широколиственных пород и лещины. Обнаруживается суббореальный максимум пыльцы дуба $(6 \%)$. В составе лесов по-прежнему превалируют береза, сосна и ольха.

В палинозоне SB2 прослеживается суббореальный максимум пыльцы ели $(18 \%)$. Содержание пыльцы сосны, березы и ольхи в пределах $25-35 \%$. Количество пыльцы широколиственных пород около $10 \%$. Пыльца травянистых и водных растений встречается лишь в виде единичных зерен. Границу между суббореальной и субатлантической хронозонами характеризует значительное уменьшение количества пыльцы ели и увеличение содержания пыльцы сосны и березы.

Палинозона SA1 выделяется субатлантическим максимумом пыльцы ольхи (29\%, Ряэкъярв), хотя этот максимум не всегда выражен 


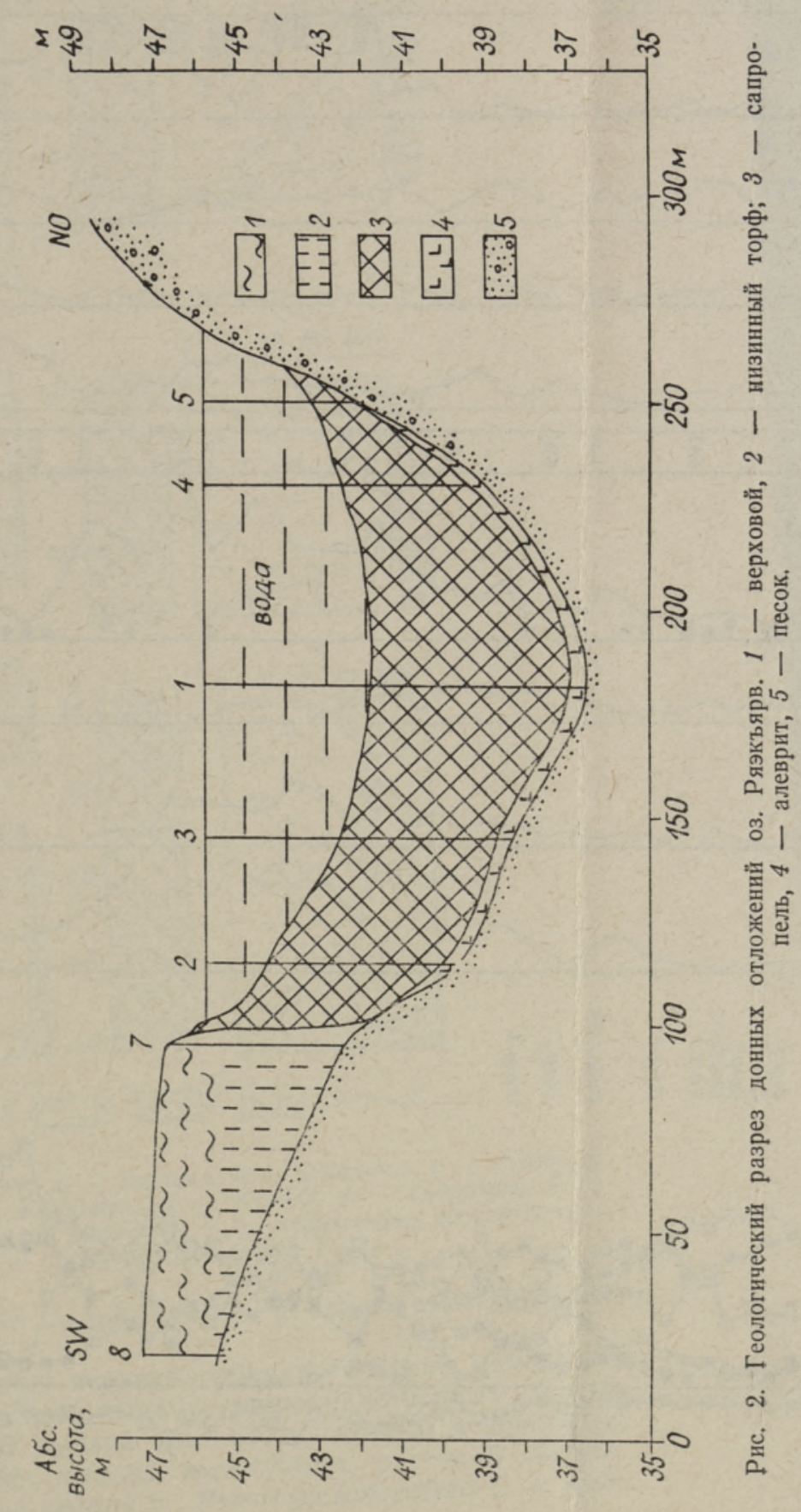



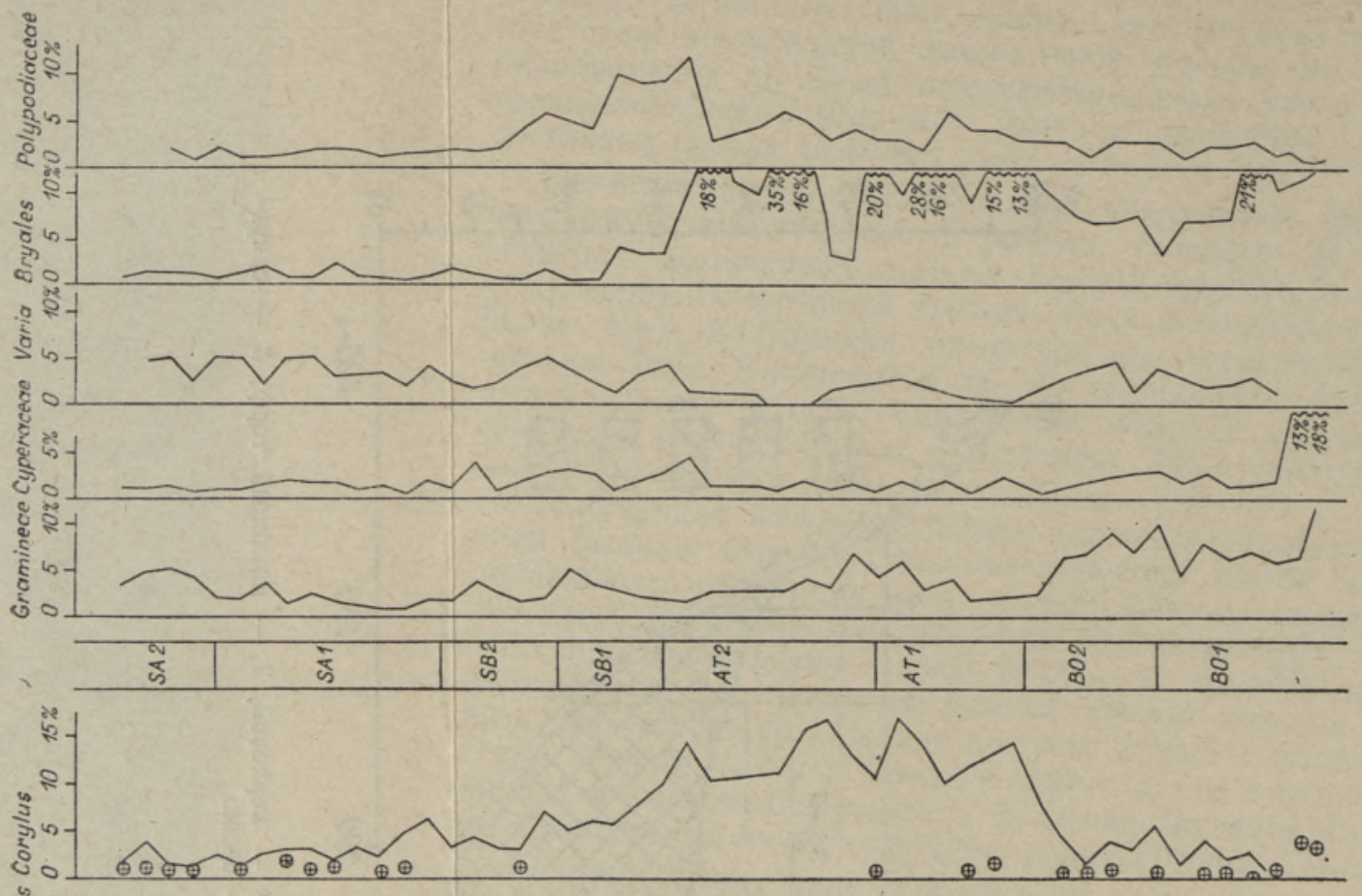

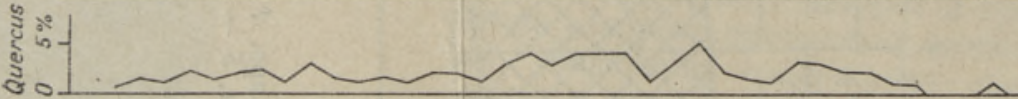
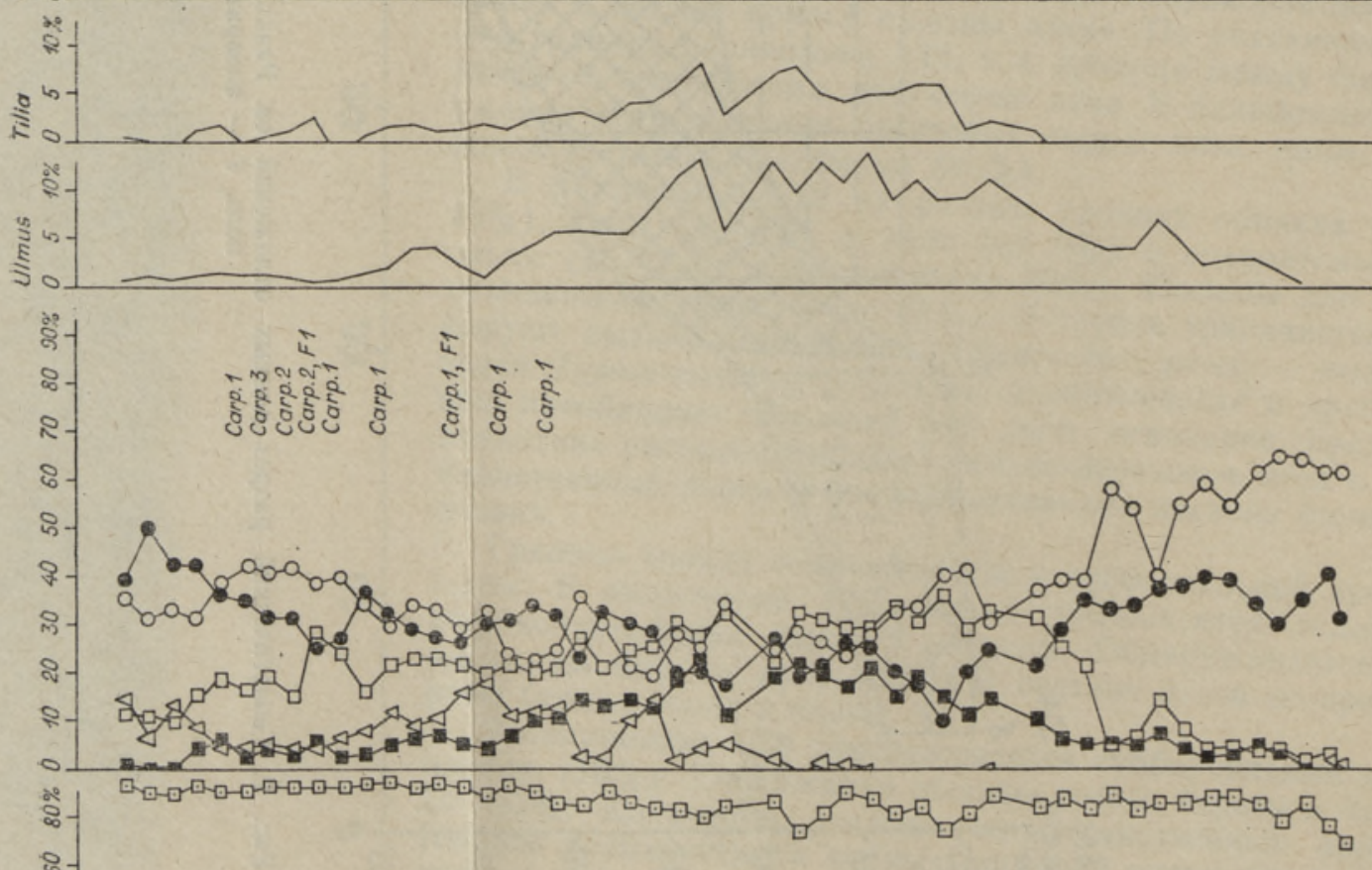

$8-$

가

I-

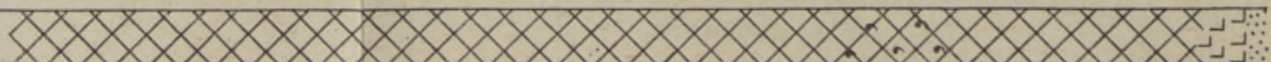



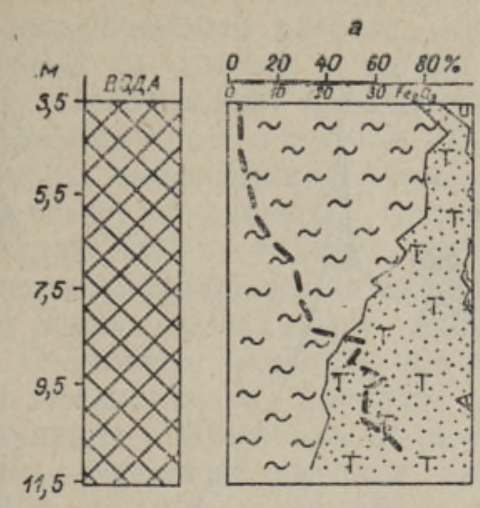

\section{$\sigma$}
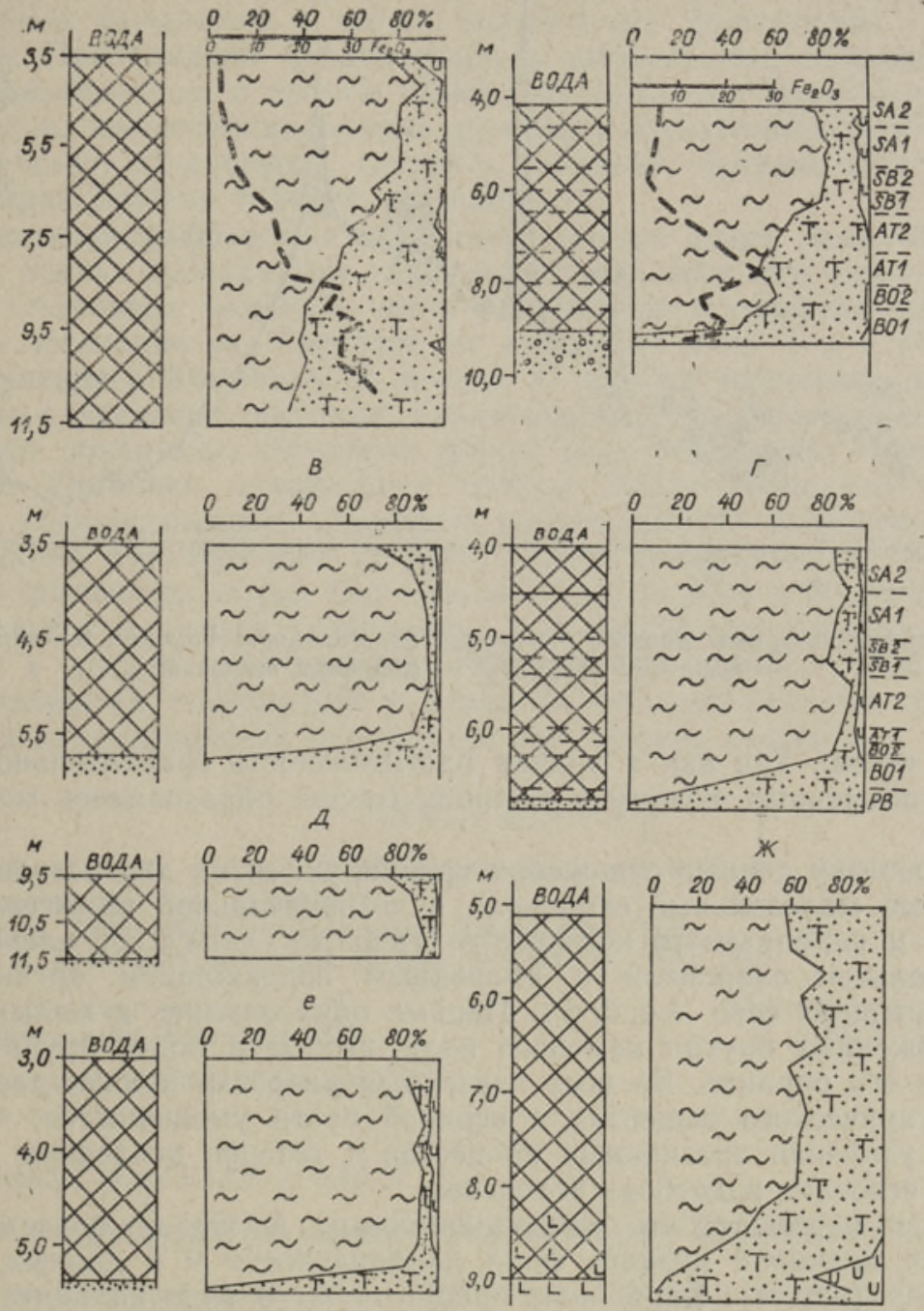

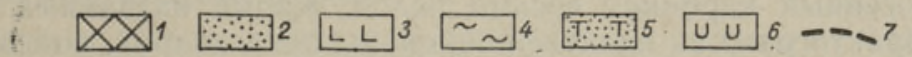

Рис. 4. Состав донных отложений озер. $a-$ Ряэтсма, б- Ряэкъярв, $в-$ Ахнеярв, 己- Хаугъярв, $\partial-$ Валгеярв, e - Коннъярв, ж- Куртна. 1 - сапропель, 2 песок, 3 - алеврит, 4- органическое вещество, 5- терригенное составляющее, 6 - карбонаты, 7 - кривая распределения $\mathrm{Fe}_{2} \mathrm{O}_{3}$.

четко (Хаугъярв). Содержание пыльцы сосны и березы заметно увеличивается.

B палинозоне SA2 обнаружен верхний субатлантический максимум пыльцы ели $(14 \%)$. Содержание пыльцы широколиственных пород остается в пределах $1-6 \%$. В пыльце трав сосредоточены в основном злаки и разнотравье. Отмечена пыльца культурных растений Secale cereale L. и сорняков Centaurea cyanus L., Plantago lanceolata L. и других. Встречаются споры Polypodiaceae и Bryales.

Из палинологических данных явствует, что на камовом поле Иллука во время климатического оптимума господствовали сосново-березовые и березово-сосновые леса с примесью широколиственных пород. Это вполне естественно, учитывая, что здесь преобладают песчаные подзо- 


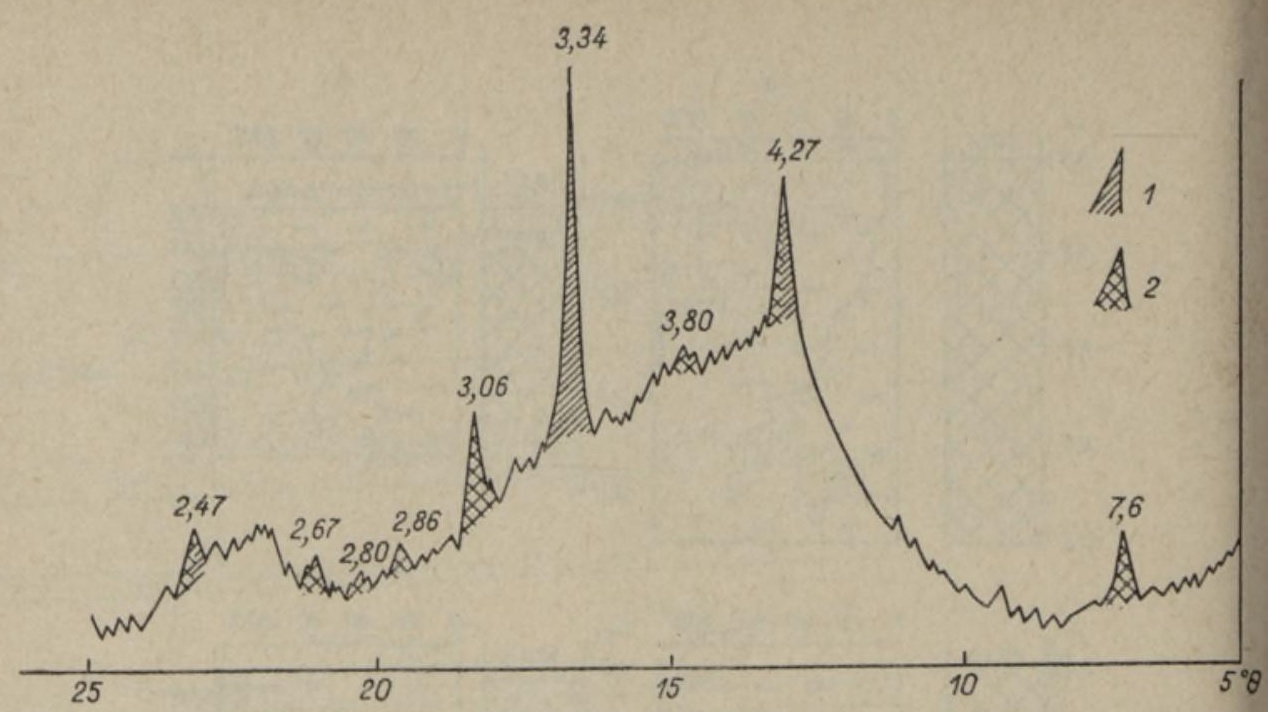

Рис. 5. Дифрактограммы донных отложений оз. Ряэкъярв. Глубина $8,5-8,75$ м. 1 рефлексы кварца, 2 - рефлексы брушита.

листые почвы. Так как и водная растительность сравнительно скудна, вполне объяснимо, почему в здешних озерах образовалось мало осадков.

По составу донные отложения группируются на две разновидности: 1) чистые малозольные сапропели с незначительной примесью терригенного и карбонатного компонента (рис. 4 в, г, $\partial, e), 2$ ) алевритистые среднезольные сапропели с умеренным содержанием органического составляющего (рис. $4 a, \sigma, ж)$. Первые образовались в малых озерах, расположенных внутри камового поля, вторые в более крупных водоемах на его окраине. Во всех изученных разрезах кривая распределения органического вещества в верхней части уменьшается, что говорит об усилении эрозионных процессов в течение последних 2000 лет за счет освоения водосбора человеком.

Малая карбонатность водноледниковых песков и подземных вод является причиной низкого фона карбонатности и в донных отложениях озер (рис. 4). Карбонаты присутствуют в виде кальцита и доломита. Гомогенный карбонат весьма редок. Кроме названных минералов на дифрактограммах идентифицированы пики кварца, полевых шпатов, гидрослюд, хлоритов, пирита и гипса. Все названные минералы довольно часты в донных отложениях озер Әстонии, кроме брушита $\mathrm{CaH}\left[\mathrm{PO}_{4}\right] \cdot 2 \mathrm{H}_{2} \mathrm{O}$ (рефлексы 7,60, 4,27, 3,80,3,06, 2,86, 2,80, 2,67, 2,47 А) (рис. 5), который идентифицирован впервые из отложений озер камовых полей Иллука и Вийтна.

Другим отличительным признаком данных сапропелей является высокое содержание соединений железа (до 27\%) в отложениях озер Ряэкъярв и (до $34 \%$ ) Ряэтсма. Во влажных пробах железо двухвалентное, аморфное, после высушивания образует оокерные пленки, а после прокаливания при температуре $900^{\circ} \mathrm{C}$ выкристаллизовывается в виде гематита. Кривые содержания железа и терригенного компонента одинаковы (рис. $4 a, б)$. Судя по разрезу оз. Ряэкъярв, максимальное железонакопление происходило в конце бореала, в начале атлантики при высоком уровне воды в озерах. Такое количество $\mathrm{Fe}_{2} \mathrm{O}_{3}$ позволяет нам говорить о рудообразовании в некоторых озерах камового поля Иллука в раннем голоцене.

На основе проведенных исследований (Саapce и др., в печати) 
можно заключить, что озера камовых полей Әстонии отличаются простотой геологического разреза, отсутствием алеврито-пелитовых позднеледниковых отложений и четко выраженных фациальных переходов осадков. Преобладают органические и органогенные сапропели, в низовьях железистые, с весьма низким содержанием карбонатов. Набор минералов, идентифицированных рентгенодифрактометрически, сравнительно богат: гидрослюды, хлориты, каолинит, полевые шпаты, кварц, гипс, пирит, брушит, сидерит, вивианит (?).

В палеогеографическом отношении данные озера малоинформативны. На портах просадочных гляциокарстовых котловин террасы весьма редки. Отдельные нанболее четко выраженные фрагменты террас найдены в котловине оз. Хаугъярв на высоте 43 и 45 м и в котловинах озер Ахнеярв и Коннъярв на высоте 47 м. Эти террасовые уровни не связаны с уровнями крупных приледниковых озер, в данном случае отмечают локальные изменения уровня воды в водоемах с амплитудой до 4 м. Учитывая содержание пыльцы прибрежноводных растений, уровни распространения отдельных разновидностей сапропеля, химический состав и содержание детрита, можно предположить, что уровень воды в изученных озерах был сравнительно низким в бореале, в конце атлантики и в начале суббореала, а сравнительно высоким в атлантике и в начале субатлантики. Явные следы хозяйственной деятель. ности человека появляются в середине субатлантической хронозоны, когда в палиноспектрах появляются культурные растения.

\section{ЛИТЕ РА Т У Р А}

Саарсе Л., Сарв А., Вейссон М. Геологическое развитие озер в южной части Лахемааского парка (в печати).

Mäemets, A. Eesti NSV järved ja nende kaitse. Tln., 1977.

Tšeban, E. Eesti NSV pōhjavesi ja selle kasutamine. Tln., 1975.

Ннститут геологии

Академии наук Эстонской ССР

Управление геологии Эстонской ССР
Поступила в редакцию $31 / \mathrm{X} 1983$

Leili SAARSE, Aino SARV, J. KARIN

\section{SETTIMINE JA JÄRVEDE ARENG ILLUKA MOHNASTIKUS}

Artiklis on käsitletud seitsme Illuka mõhnastiku järve setete lasumust, koostist, stratigraafiat ning veetaseme kōikumisi.

\section{Leili SAARSE, Aino SARV, J. KARIN}

\section{SEDIMENTATION AND GEOLOGICAL DEVELOPMENT OF LAKES IN THE ILLUKA KAME FIELD}

The authors deal with the results of geological, palynological, chemical and mineralogical investigations of seven lakes situated in the Illuka kame field in the northeastern part of Estonia. They are characterized by homogeneous Holocene lacustrine deposits lacking in Late-Glacial silty-clayey deposits. Gyttja with a thickness of $1.4-8 \mathrm{~m}$ began to accumulate in the Preboreal and continued at various rates of sedimentation $(0.1-0.8 \mathrm{~mm} / \mathrm{y})$ throughout the Holocene. Two varieties of gyttja are most common: the fine detritus gyttja rich in organic matter $(70-90 \%)$ in the uppermost part of the sequences, and the silty-sandy gyttja rich in ferruginous compounds (up to $34 \%$ ) in the lowermost part. By X-ray technics the hydromicas, chlorites, kaolinite, quartz, feldspar, gypsum, pyrite, brushite and siderite were identified. Taking account of the distribution and frequency of the macrophyte pollen, the levelling of terraces, changes in the level of the sediment limits and the content of coarse matter, it has been concluded that the water level in those lakes was rather high during the Atlantic and at the beginning of the Subatlantic chronozone, the lowest water level occurring in the Boreal, with features of lowering at the Atlantic-Subboreal boundary. The birch-and-pine forest prevailed in the catchment area throughout the Holocene. 